\title{
Sinkretisme dalam Adat Masyarakat Bajau di Sabah
}

\author{
Syncretism in Traditional Custom of Bajau Community in Sabah
}

SYAMSUL AZIZUL MARINSAH* \& MOHD ANUAR RAMLI ${ }^{1}$

\begin{abstract}
The spread of Islam in the Archipelago especially in Sabah has produced two forms of interactions which are Islamization and sincretizing. Islamization process that occured subtly and gradually at that time caused Bajau community easy to accept Islam without being forced. However, there are some practices of Bajau community that closely linked to the animism belief still being practiced to produced a process of syncretism. The objective of this article is to introduce Islamic methods by suggesting guidelines or legislation parameter in interacting with syncretism in traditions of Bajau community in Sabah. In facing syncretism between the traditional practices of Bajau with the teaching of Islam, there are at least three Islamic approaches towards the developed culture among Bajau community which are to accept, modify or reject. Therefore, an appropriate method of Islamic law need to prevail to handle the phenomenon in ensuring the balance between idealism contained in Islamic law with the reality of its implemantation in Bajau community. The study found that there are many symptoms of syncretism occured in tradition and culture of Bajau community which are difficult to know whether it is a genuine Islamic teachings or a relic of pre-Islamic tradition.
\end{abstract}

Keywords: Bajau, cultural practice, Malaysian ethnics, Sabah, syncretism

Dalam kajian para sarjana, perbincangan berhubung fenomena sinkretisme sering dibahaskan dalam pelbagai aspek antaranya teologi (Leopold \& Jensen 2004), terminologi dalam agama Kristian (Zenner 2005), model dalam kajian sinkretisme (Robbins 2011) dan sebagainya. Berhubung dengan istilah sinkretisme itu sendiri, terdapat pihak yang setuju untuk mengekalkan maksudnya sebagai suatu penyatuan terhadap doktrin yang bertentangan (Schineller 2000) dan terdapat pihak yang cuba untuk memberi takrif dan ganti kepada istilah baharu agar istilah sinkretisme tidak dianggap satu konotasi yang negatif (Schreiter 1989).

Pada kebiasaannya, konsep sinkretisme ini diguna pakai dalam usaha untuk menyatukan agama Kristian yang pelbagai aliran (Levinskaya 1993). Pada hari ini, konsep tersebut diperluaskan penggunaanya bukan sahaja menggambarkan penyatuan antara agama, tetapi merangkumi penyatuan aspek falsafah, seni, budaya dan sebagainya. Dalam aspek agama, penyatuan dan pembauran kepercayaan setempat dengan agama Kristian misalnya dapat dilihat dalam amalan dan ritual penyembuhan penyakit yang berkaitan dengan spiritual (Norazit 1989). Dalam amalan dan ritual tersebut, terdapat unsur-unsur percampuran, pembauran antara kepercayaan setempat dengan ajaran Kristian.

\footnotetext{
${ }^{1}$ Syamsul Azizul Marinsah*(Corresponding author), doctoral student at Dept. of Fiqh \& Usul, Academy of Islamic Study, Universiti Malaya, 50603 KUALA LUMPUR, Malaysia, e-mel: kehak@yahoo.com; Mohd Anuar Ramli, Ph.D., senior lecturer at Dept. of Fiqh \& Usul, Academy of Islamic Study, Universiti Malaya, 50603 KUALA LUMPUR, Malaysia, e-mel: mohdanuar@um.edu.my.
} 
Walau bagaimanapun, fenomena sinkretisme ini dapat turut dilihat dalam amalan agama lain seperti agama Islam khususnya bagi masyarakat Melayu di Nusantara. Antara amalan masyarakat Melayu yang dapat dikenal pasti hasil daripada fenomena sinkretisme ialah seperti penggunaan jampi serapah yang diselitkan dengan nama Nabi, Allah SWT dan ayat-ayat al-Quran, kepercayaan kepada sial, kepercayaan kepada keramat dan sebagainya. Fenomena sinkretisme agama khususnya dalam agama Islam boleh menyebabkan kekeliruan dalam memahami sesuatu ajaran yang dipercayai oleh seseorang individu Muslim. Ini terbukti melalui fakta sejarah yang dicatatkan oleh Colpe (1987) yang mendakwa seorang pemerintah Dinasti Mughal di India telah mencampuradukkan ajaran agama Islam dengan Hindu dan Zoroastanisme. Akibatnya, muncul agama baru yang dinamakan agama 'Din Ilahi'.

Begitu juga dengan bukti kelahiran agama Sikh yang terhasil daripada gabungan fahaman unsur nirguna (iaitu menganggap tuhan tanpa rupa dan bentuk) dalam tradisi agama Hindu dengan konsep beriman kepada tuhan yang satu dalam kepercayaan yang terdapat dalam ajaran Islam (Suraya 2003). Di Timur Tengah pula, sinkretisme berlaku hasil kesinambungan kepercayaan zaman purba hingga menjurus kepada sinkretisme dalam agama seperti yang wujud dalam agama Druze (Encyclopedia of World Minorities 2013), Ahl Haqq/Yarsanism (Hamzeh'ee 1995) dan sebagainya. Agama-agama ini dianggap terpesong daripada ajaran Islam yang tulen. Berdasarkan contoh-contoh yang diberikan, tidak dapat dinafikan bahawa fenomena sinkretisme boleh menjejaskan pegangan akidah yang asal dan boleh membawa kepada pembentukan agama yang baru.

Hal yang sama turut berlaku kepada masyarakat Bajau. Namun dalam konteks kajian ini, fenomena sinkretisme tidak sampai ke tahap lahirnya agama baru yang dipercayai oleh orang Bajau. Ajaran Islam tetap dijadikan sebagai tunjang asas dan panduan hidup, cuma dalam penyelenggaraan sesuatu adat, terdapat unsur-unsur pra-Islam yang dipercayai mempengaruhi kehidupan masyarakat tersebut.

\section{Konsep Sinkretisme Menurut Perspektif Barat}

Secara literal, sinkretisme dalam bahasa Inggeris disebut sebagai syncretism yang berasal daripada perkataan Greek synkretismos yang bermaksud merangkaikan, menggabungkan dan menyatukan (Dictionary of Philosophy and Religion 1980) Istilah ini juga digunapakai dalam bahasa Perancis (syncretisme), bahasa Jerman (synkretismus), dan bahasa Itali (sinkretismo) (Encyclopedia of Philosophy and Pyschology 1986). Kesemua bahasa ini menjelaskan sinkretisme dari sudut bahasa membawa maksud menyatukan, mencampurkan, menggabungkan dan seumpamanya. Istilah sinkretisme dalam bahasa Inggeris juga merujuk kepada makna percampuran budaya atau amalgamasi budaya (Oxford Dictionary 2001) atau percampuran amalan dan praktik dari pelbagai agama (The New Encyclopaedia Britannica 1976). Senada dengan takrif ini, The Concise Oxford English Dictionary (2011) memberikan takrif sinkretisme sebagai "the amalgamation or attempted amalgamation of different religions, cultures, or schools of thought". Menurut Brown (2006 difahami bahawa sinkretisme dalam bahasa Inggeris merujuk kepada dua jenis sinkretisme iaitu pertama, sinkretisme antara budaya yang mana wujud hasil daripada percampuran dan pembauran antara budaya. Kedua, sinkretisme antara agama yang wujud hasil daripada percampuran dan pertembungan antara agama dan worldview sesuatu agama.

Sementara itu, Cross (1997) mendefinisikan sinkretisme sebagai usaha untuk menyatukan pelbagai doktrin yang bertentangan terutamanya dalam bidang falsafah dan juga agama. Pengertian ini hampir sama dengan definisi yang dikemukakan oleh Pinto (1985), Moreau (2000), Schreiter (1993) dan Schineller (1992) namun dalam ungkapan yang berbeza. Sarjana Barat Mullins (2001) pula memberikan definisi yang terperinci berhubung sinkretisme menurut terminologi. Menurut beliau, sinkretisme dapat difahami sebagai gabungan unsurunsur dari dua atau lebih agama, ideologi atau sistem nilai. Dalam bidang sains sosial, 
perbahasan sinkretisme adalah bersifat neutral bagi menggambarkan pencampuran antara agama akibat daripada hubungan budaya. Tetapi dalam perbahasan teologi dan missiological, menurut beliau, ia satu istilah yang digambarkan mencemarkan ketulenan sesuatu agama khususnya agama Kristian.

\section{Konsep Sinkretisme Menurut Perspektif Islam}

Dalam peradaban sejarah, fenomena sinkretisme dikenal pasti sejak zaman Arab Jahiliyyah lagi. Hal ini terbukti dengan amalan ibadat haji yang diperkenalkan oleh Nabi Ibrahim pada sebelum abad 20 SM kemudiannya telah dicampur-aduk (sinkretisme) dengan elemen-elemen syirik sebelum pengutusan Rasulullah. Perlaksanaan-perlaksanaan ibadat haji seperti talbiyah, ihram, tawaf, wuquf dan sebagainya telah menyeleweng daripada ajaran asal Nabi Ibrahim sehingga berlaku sinkretisme dan sukar dibezakan antara amalan yang asal dan amalan yang ada unsur pembauran dengan adat tradisi (Salman 2003).

Sinkretisme merupakan perkara tabi'i yang berlaku kepada semua agama di dunia ini. Walau bagaimanapun, konotasi sinkretisme ini lebih berbentuk negatif yang menyebabkan ramai sarjana sama ada Barat atau Muslim menolak segala bentuk sinkretisme terutamanya penggunaan istilah ini dalam ruang lingkup agama. Menurut pengamatan pengkaji, tiada istilah yang khusus dan tepat dalam menterjemahkan istilah sinkretisme dalam perspektif Islam khususnya dalam bahasa Arab. Hal ini kerana, sinkretisme ini muncul pada abad yang terkemudian sedangkan pada zaman Nabi, segala percampuran dan pembauran dalam agama lebih dikenali dengan istilah bidaah, syirik, khurafat dan sebagainya. Istilah ini popular digunakan pada abad ke-16 dan ke-17 dalam peradaban Barat terutamanya dalam ajaran Kristian (Herlianto 1996). Meskipun begitu, terdapat para sarjana Muslim yang mengaitkan istilah sinkretisme dengan beberapa istilah dalam bahasa Arab. Antaranya istilah tawfiqiyyah (Mualimin 2016), talfiqiyyah (Ros Aiza 2015) dan takhlit (Muhsin 2011). Sarjana antropologi Muslim dari Indonesia iaitu Bambang Pranowo (2016) mengatakan bahawa istilah bahasa Arab yang paling hampir dengan istilah sinkretisme ialah al-tawfiq baina al-mu'taqadat aitu mencari kesesuaian/keserasian antara pelbagai keyakinan dan kepercayaan. Hal yang sama diperkatakan oleh Sumanto (2016). Menurut beliau, tidak wujud istilah khusus dalam bahasa Arab menterjemahkan istilah sinkretisme. Istilah al-tawfiq baina al-mu'taqadat adalah istilah yang sesuai dalam bahasa Arab menggambarkan fenomena sinkretisme yang berlaku dalam masyarakat.

Istilah ini juga diguna pakai oleh Mualimin (2016) dalam menjelaskan fenomena sinkretisme di kalangan masyarakat Jawa. Menurut beliau, selain daripada istilah al-tawfiqiyyah, istilah sinkretisme juga boleh diterjemahkan kepada bahasa Arab dengan istilah al-imtizajiyyah iaitu percampuran atau pembauran dalam perkara-perkara yang melibatkan agama dan kepercayaan. Hal ini kerana istilah "agama sinkretik" dikenali dalam bahasa Arab dengan istilah al-Diyanah al-Imtizajiyyah. Namun begitu, baginya istilah-istilah ini merupakan istilah yang diterjemahkan secara harfiyyah dan bukannya berbentuk mutlak menggambarkan sinkretisme seperti penggunaannya dalam disiplin ilmu antropologi.

Sehubungan itu, definisi yang terperinci diberikan oleh Jurnal al-Insan wa al-Mujtama' (Zarawih 2016) berhubung definisi sinkretisme (talfiqiyyah) dalam bidang sains sosial iaitu: "talfiqiyyah adalah gabungan elemen-elemen yang berbeza antara satu sama lain yang diperolehi daripada sumber atau aliran yang berbeza dan meletakkannya dalam satu aliran, seperti hasil cetusan atau peleburan dua idea atau dua pegangan agama yang berbeza, atau dua adat yang bercanggah atau integrasi bahagian-bahagian atau integrasi pendapat-pendapat atau integrasi kebudayaan yang saling bercanggah antara satu sama lain untuk membina satu bentuk aliran atau doktrin yang baru". 
Sebagai rumusan, walaupun istilah sinkretisme diterjemahkan dalam bahasa Arab kepada talfiqiyyah, tawfiqiyah dan takhlit, namun ia bukan suatu istilah yang tepat untuk menjelaskan fenomena sinkretisme yang berlaku dalam masyarakat pada hari ini. Hal ini kerana takrif sinkretisme menurut bahasa Arab hanya merujuk kepada harmonisasi dalam aspek kepercayaan "التوفيق بين المعتقدات seperti yang dijelaskan oleh para sarjana di atas. Dalam erti kata lain, kebanyakan sarjana membincangkan sinkretisme dalam bahasa Arab merujuk kepada wahdah al-adyan (percampuran agama). Sedangkan fenomena sinkretisme pada hari ini yang berlaku dalam masyarakat bukan sahaja berlaku dalam aspek agama dan falsafah tetapi berlaku antara agama dan juga budaya. Penggunaan isitilah sinkristisme sama ada dalam bahasa Inggeris, Melayu atau Arab merujuk kepada proses percampuran, penyatuan, pembauran atau penggabung jalinan suatu unsur dengan unsur yang lain. Percampuran ini menyebabkan lahirnya satu pegangan unsur yang baharu yang terhasil daripada penyatuan dan pembauran unsur-unsur yang saling bertentangan tadi.

\section{Proses Sinkretisme dalam Masyarakat Bajau Di Sabah}

Secara dasarnya, proses sinkretisme yang berlaku dalam masyarakat Bajau boleh dilihat dalam rajah di bawah:

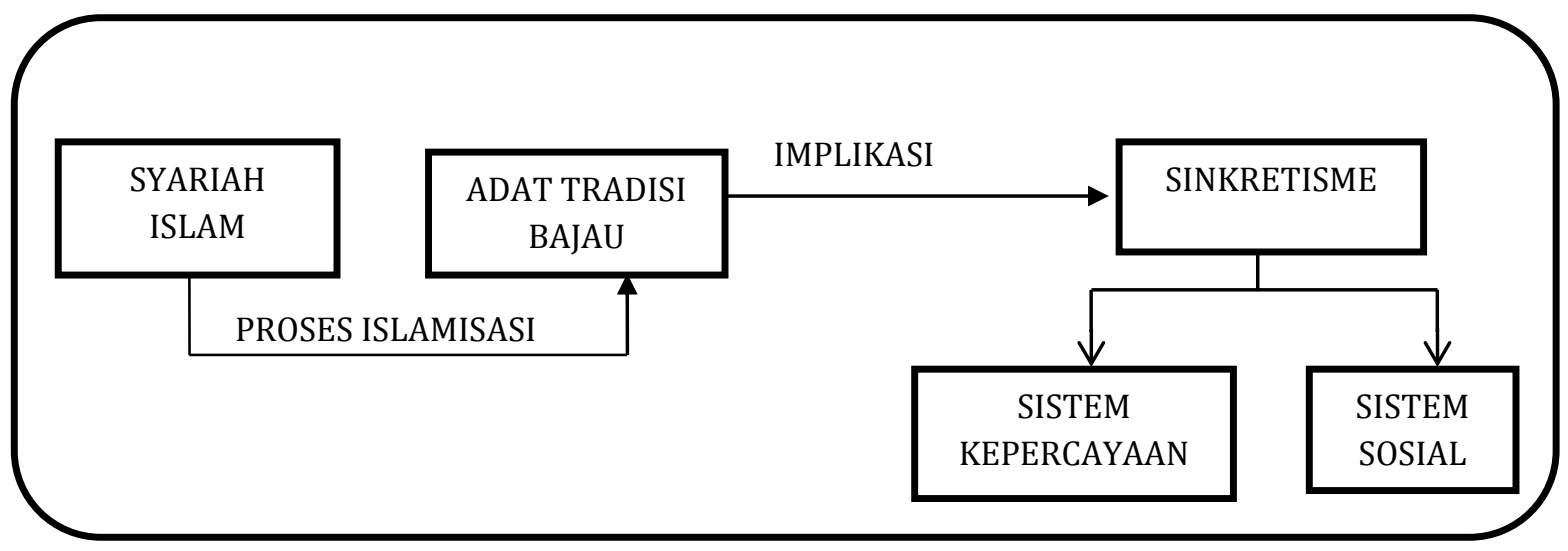

Rajah di atas menunjukkan model atau kerangka sinkretisme yang berlaku dalam masyarakat Bajau. Lazimnya, interaksi antara Islam dengan suatu kebudayaan menghasilkan tiga bentuk implikasi iaitu kerjasama, persaingan dan konflik (Faisal 1997). Namun begitu, pertembungan antara ajaran Islam dan adat budaya Bajau tidak berlaku konflik atau persaingan malah berlakunya kerjasama dan penyatuan antara adat dan budaya masyarakat Bajau dengan ajaran Islam sehingga melahirkan implikasi fenomena sinkretisme. Sebelum kedatangan Islam ke Sabah, masyarakat Bajau merupakan penganut fahaman animisme. Oleh yang demikian, kebanyakan amalan adalah pengaruh daripada amalan pra-Islam. Kedatangan Islam menyebabkan berlakunya interaksi antara agama masyarakat Bajau ketika itu dengan ajaran Islam melalui proses Islamisasi. Proses Islamisasi yang berlaku secara halus dan beransur-ansur menyebabkan masyarakat Bajau pada ketika itu mudah menerima Islam dengan rela tanpa dipaksa.

Walaupun kebanyakan adat tradisi Bajau berjaya diislamisasikan oleh pendakwah awal yang datang ke Sabah, namun terdapat fenomena lain yang menggugat kesucian agama Islam dalam masyarakat Bajau iaitu fenomena sinkretisme. Walaupun banyak amalan masyarakat Bajau sebelum memeluk agama Islam berjaya diislamisasikan, namun pada masa yang sama amalan-amalan tersebut bercampur-baur (sinkretis) antara ajaran Islam dan juga pra-Islam. Dalam pada itu, masyarakat Bajau yang berpegang teguh dengan adat tradisi tidak 
meninggalkan sepenuhnya amalan tradisi, tetapi cuba menggabung jalinkan antara adat tradisi Bajau dengan ajaran Islam. Hal ini dapat dilihat sebagai misalnya dalam mantera-mantera amalan ritual perubatan tradisional masyarakat Bajau. Antara faktor yang menyebabkan berlakunya fenomena sinkretisme dalam budaya Bajau adalah disebabkan metode para pendakwah menyebarkan Islam di Sabah pada ketika itu (Muhidin 1990). Menurut sejarah, para pendakwah dari kalangan golongan sufi dapat menarik perhatian masyarakat tempatan Sabah termasuk orang Bajau untuk memeluk agama Islam. Sikap yang bertoleransi terhadap kebudayaan dan kepercayaan lama dibiarkan wujud kemudian diwarnai dengan ajaran-ajaran Islam adalah sikap yang menarik perhatian masyarakat untuk memeluk agama Islam.

Oleh yang demikian, proses sinkretisme yang berlaku tersebut menghasilkan dua implikasi iaitu sinkretisme positif dan sinkretisme negatif. Sikap toleransi dan akomodatif terhadap kepercayaan dan budaya setempat di satu sudut kelihatan dampak negatif iaitu berlaku proses sinkretisme antara ajaran Islam dengan kepercayaan lama sehingga sukar untuk dibezakan mana satu ajaran Islam yang tulen dan yang mana satu merupakan kesan peninggalan kepercayaan dan tradisi silam. Namun aspek positifnya, ajaran-ajaran yang disinkretiskan tersebut telah menjadi wadah atau jambatan yang memudahkan masyarakat Bajau menerima Islam sebagai agama yang baru. Segala unsur budaya tempatan masyarakat Bajau yang kelihatan bertentangan dengan Islam tidak sewajarnya disimpulkan sebagai kegagalan proses Islamisasi, tetapi sewajarnya ia dilihat sebagai proses Islamisasi yang belum selesai.

Rajah di atas juga menunjukkan klasifikasi berlakunya fenomena sinkretisme dalam kalangan masyarakat Bajau iaitu pada peringkat pertama dalam sistem kepercayaan (akidah) dan peringkat kedua pada sistem sosial ('urf dan adat). Klasifikasi ini merupakan teori yang diutarakan oleh Koentjaraingrat (1984) dalam melihat sistem masyarakat Jawa secara umum. Hal yang sama berlaku dalam masyarakat Bajau. Unsur sinkretisme yang berlaku bukan sahaja pada sistem kepercayaan Bajau, tetapi ia turut berlaku dalam sistem sosial ('urf dan adat) masyarakat Bajau. Unsur-unsur sinkretisme yang berlaku pada sistem keyakinan Bajau dapat dilihat umpamanya dalam keyakinan terdapat kuasa selain daripada Allah dalam memberi manfaat dan mudarat kepada manusia. Mereka percaya bahawa roh nenek moyang yang telah meninggal dunia mampu memberkati atau memberi bala kepada generasi yang masih hidup sekiranya mereka melanggar pantang larang tertentu. Kepercayaan roh boleh memberi manfaat dan mudarat merupakan saki-baki kepercayaan animisme-dinamisme.

Dalam aspek sistem sosial pula dapat sinkritisme dapat dilihat pada adat kelahiran, perkahwinan dan kematian yang cuba disatukan dengan ajaran Islam untuk kelangsungan hidup bermasyarakat. Hal ini boleh dilihat umpamanya dalam upacara menolak bala, upacara menimbang bayi yang lahir pada bulan Safar, amalan perbomohan dan penggunaan mantera yang sinkretis, amalan magombbo', upacara ngalai, amalan ngeduang, amalan bangkaibangkaian dan sebagainya. Kesemua amalan ini telah berlaku sinkretisme antara ajaran Islam dan pra-Islam di samping dipengaruhi oleh budaya setempat. Unsur sinkretisme lebih ketara dalam adat dan budaya Bajau terutamanya dalam aspek upacara dan ritual tertentu seperti ritual menghadapi krisis, ritual mengharapkan keselamatan, ritual perubatan tradisonal, dan ritual yang menggambarkan kesyukuran (Hj. Hussin 2015).

\section{Panduan atau Parameter Syarak dalam Berinteraksi dengan Sinkretisme}

Pengkaji telah membangunkan satu panduan syarak dalam berinteraksi dengan fenomena sinkretisme yang berlaku dalam adat dan budaya sesuatu masyarakat. Panduan dan parameter ini penting untuk menunjukkan bahawa Islam bukanlah agama yang rigid untuk menolak semua adat tradisi pra-Islam. Adat-adat pra-Islam yang mempunyai nilai yang positif atau baik dan selari dengan syarak perlu dikekalkan atau dimodifikasi agar tidak bertentangan dengan Islam. Panduan ini perlu untuk memastikan terdapat pemisah yang jelas antara adat dan juga ibadat. 
Saki-baki sinkretisme pra-Islam yang mempunyai nilai positif yang baik boleh terus diamalkan selagi tidak bertentangan dengan syarak. Manakala sinkretisme pra-Islam yang mempunyai nilai negatif perlu diperhalusi sama ada ia boleh diharmonisasikan atau tidak kerana dikhuatiri boleh terjebak dalam 'urf fasid sama ada kerana ia khurafat, bidaah, syirik dan sebagainya. Rumusan panduan dan parameter tersebut seperti berikut:

\section{Sinkretisme Mestilah dalam Ruang Lingkup Ibadat (Fiqh), Bukannya Akidah}

Sebagaimana yang dijelaskan sebelum ini, sinkretisme merupakan istilah yang sinonim dengan istilah talfiqiyyah dan tawfiqiyyah menurut perspektif Islam. Para ulama telah sepakat bahawa ruang lingkup talfiqiyyah hanya terbatas pada ruang lingkup masalah-masalah furu'iyyah ijtihadiyyah zanniyah (ijtihad dan dalil-dalil zanni) manakala pada masalah usuliyyah seperti masalah ketuhanan (ilahiyah), iman atau akidah, tidak boleh berlaku talfiqiyyah dan tawfiqiyyah (Wahbah al-Zuhayli 1993). Oleh itu, dalam perkara yang melibatkan akidah, tiada unsur harmonisasi atau kompromi antara ajaran Islam dengan kepercayaan (akidah) agama lain. Hal ini ditegaskan dalam surah al-Kafirun yang mana tauhid (keesaaan kepada Allah) dan syirik tidak dapat digabung jalinkan atau diharmonikan. Menurut Hamka (1965), surah ini menunjukkan bahawa tauhid dan syirik tidak dapat diharmoniskan kerana akidah tauhid tidak boleh bercampur-baur (sinkretisme) dengan kepercayaan animisme misalnya seperti peyembahan kepada berhala dengan solat, penyembelihan binatang dengan tujuan pemujaan dengan membaca basmalah dan seumpamanya.

Oleh itu, dalam persoalan akidah prinsip yang harus diambil perhatian hubungan antara agama Islam dan agama lain ialah prinsip perbezaan dan bukannya persamaan. Bagi mengelakkan permasalahan dalam hubungan tersebut ialah pengiktirafan dan berlapang dada kepada perbezaan-perbezaan yang wujud dan bekerjasama pada perkara-perkara yang ada unsur persamaan. Inilah bentuk kebebasan beragama yang dianjurkan oleh Islam dan sikap toleransi yang ditanamkan kepada umat Islam terhadap masyarakat lain. Tetapi toleransi tersebut mesti ada garis pemisah antara kepercayaan kepada Allah SWT dengan tuhan-tuhan selain daripada Islam. Sinkretisme dalam bidang akidah adalah di larang.

Dalam perkara yang menyentuh hukum-hukum syarak yang sabit dengan dalil qat'i, maka sinkretisme adalah dilarang mengikut ijma' ulama (Saipuddin 2003). Namun begitu, sekiranya ia termasuk dalam perkara ijtihadiyyah, maka sinkretisme dibenarkan tetapi dengan syarat-syarat tertentu antaranya elemen sinkretisme yang wujud tidak termasuk dalam perkara yang menjejaskan agama seperti wujudnya elemen khurafat, syirik dan bidaah. Sebagai contohnya, amalan majlis tahlil dalam kalangan masyarakat Nusantara. Walaupun kenduri arwah pada asalnya merupakan saki-baki sinkretisme dalam ajaran Hindu, tetapi ia telah menerima pengubahsuaian sehingga amalan memuja roh nenek moyang ditukar ganti kepada Allah SWT dan amalan menjamu roh nenek moyang ditukar ganti kepada amalan menjamu hadirin dengan niat sedekah. Ia sejajar dengan kaedah Qawaid al-Fiqhiyyah iaitu "Hukum itu bergantung kepada 'illah (sebab). Ada 'illah ada hukum, tiada 'illah tiada hukum" (al-Ghazali 2000).

Ringkasnya, tiada konsep toleransi dan kompromi dalam soal akidah. Akidah tidak sama dengan perbahasan fiqh yang mempunyai kepelbagaian pendapat sama ada rajih atau marjuh. Akidah merupakan satu iktikad dan fahaman yang jazam iaitu pasti dan qat'i tanpa syak. Oleh itu, sinkretisme dalam aspek akidah adalah bercanggah dengan syarak kerana tidak ada ruang elemen-elemen pra-Islam untuk diharmonikan sejajar dengan syariat Islam.

\section{Bentuk Sinkretisme Bukan dalam Ruang Lingkup Agama dengan Agama}

Dalam perbahasan sinkretisme, terdapat sarjana yang membahagikan sinkretisme berlaku dalam tiga bentuk iaitu agama dengan agama (Radwan 2009), agama dengan falsafah (Ibn 
Rushd 1980) dan agama dengan budaya (Ros Aiza 2015). Sinkretisme dalam aspek agama dengan falsafah dan budaya tidak menjadi perbahasan kerana kebanyakan sarjana bersetuju dibolehkan sinkretisme dalam aspek tersebut. Namun begitu, dalam aspek sinkretisme antara agama dengan agama, ramai sarjana sama ada sarjana Barat atau Muslim menolak unsur sinkretisme dalam aspek ini.

Dalam persepektif Islam, amalan mencampuradukkan agama dengan agama termasuk dalam wahdah al-adyan (penyatuan agama atau pluralisme agama) (Fajri 2010). Dalam erti kata lain, Islam menerima kepelbagaian agama tetapi menolak doktrin pluralisme agama. Hal ini kerana setiap agama mempunyai prinsip dan doktrin tersendiri yang perlu dipatuhi oleh setiap penganutnya (Ramli 2003).

Perlakuan mencampur-adukkan suatu ajaran agama dengan agama yang lain adalah perkara yang terlarang dalam semua agama dan boleh dihukumkan syirik ke atas pelakunya. Perlakuan mencampurkan antara agama ibarat mencampurkan antara kebenaran dan kebatilan dan ia adalah diharamkan (al-Baqarah: 42). Di samping itu, sinkretisme dalam agama juga termasuk dalam pengharaman mencampur-adukkan ritual ibadat yang terlarang seperti dijelaskan dalam surah al-Syura: 15. Perlakuan sinkretisme agama dengan agama termasuk dalam perkara syirik kerana terdapat usaha untuk menggabung jalinkan kepercayaan kepada Allah dan tuhan-tuhan dalam agama yang lain seperti yang dinyatakan dalam surah Ali 'Imran ayat : 85 .

Larangan sinkretisme agama dengan agama termasuk dalam kategori meredhai sesuatu perbuatan kufur atau maksiat. Menurut Ibn Hajar al-Haytami (1987), apabila ada unsur redha dengan kekafiran agama non muslim, maka hukumnya adalah haram dan kafir. Selain itu, menurut al-Razi (2000), kaedah الرضا بالكفر فهو كفر (reda dengan kekufuran adalah kufur), الرض (reda dengan maksiat adalah maksiat) merupakan kaedah yang disepakati oleh ijma' ulama. Berdasarkan kaedahkaedah ini dapat difahami sinkretisme antara agama dengan agama adalah bercanggah dengan syarak kerana tidak mungkin wujud kompromi antara agama dalam soal keyakinan (akidah). Kompromi tidak boleh berada pada aspek 'ubudiyyah kerana masalah 'ubudiyah adalah aspek yang qat'i tanpa wujud ruang untuk toleransi atau kompromi.

Sinkretisme agama dengan agama dilarang syarak kerana ia bercanggah dengan prinsip maqasid syariah. Para ulama telah membahagikan maqasid syariah kepada lima (al-daruriyat alkhams) iaitu menjaga agama (hifz al-din), menjaga nyawa (hifz al-nafs), menjaga akal (hifz al$a q l$ ), menjaga keturunan (hifz al-nasl) dan menjaga harta (hifz al-mal) (al-Syatibi t.th.). Syariah Islam menjaga elemen maqasid ini dengan dua cara iaitu menetapkan peraturan dan mendirikan rukun-rukunnya dan mengadakan satu kaedah untuk mengelakan kerosakan padanya (al-Raysuni 1995). Dalam konteks menjaga agama menurut perspektif maqasid syariah, ketulenan menjaga kemurnian tauhid merupakan satu kewajipan tanpa ada unsur percampuran atau pembauran antara agama. Hal ini kerana, pembauran atau percampuran doktrin antara agama boleh menjejaskan kemurnian ajaran agama Islam dan bercanggah dengan prinsip Islam yang sahih.

\section{Elemen Sinkretisme dalam Agama dan Budaya Tidak Berkait dengan Konsep al-Tashabbuh dalam Syiar Agama Bukan Islam}

Dalam interaksi agama dan budaya, fenomena sinkretisme merupakan satu perkara yang neutral. Penyatuan unsur-unsur budaya dan ajaran dalam sesuatu agama khususnya agama Islam merupakan satu proses semula jadi dalam rangka proses dakwah dan pengislaman. Walau bagaimanapun, elemen-elemen penyatuan tersebut perlu diberi perhatian terutamanya dalam aspek al-tasyabbuh. Al-Ghazi (t.th.) mendefinisikan al-tasyabbuh sebagai ungkapan dan perlakuan tentang tingkahlaku yang diinginkan dan dilakukannya. Dalam konteks tulisan ini, ia 
dirujuk sebagai "penyerupaan orang Muslim terhadap orang kafir pada sesuatu perkara yang tidak termasuk dalam maslahah yang muktabar" (Asyraf t. th.).

Berhubung dengan konsep al-tasyabbuh dengan orang bukan Islam, terdapat keharusan tasyabbuh dengan mereka dalam hal-hal tertentu terutamanya dalam perkara yang berkaitan dengan maslahah 'ammah. Elemen al-tasyabbuh dengan syariat bukan Islam ada yang diharuskan, ada yang dilarang syarak. Berhubung tasyabbuh dalam sinkretisme, segala bentuk penyerupaan dengan golongan bukan Islam dan berkait-rapat dengan syiar mereka, adalah diharamkan secara mutlak. Hal ini kerana agama Islam melarang keras menyerupai bukan Islam terutamanya dalam upacara keagamaan mereka (Basri 2010).

\section{Diharuskan Meneruskan Adat Tradisi Pra Islam dengan Syarat Tidak Berlaku Perubahan (Tahrif) dan Penukaran (Tabdil) dalam Syariat Islam}

Islam bukanlah agama yang rigid menolak segala kebudayaan yang lahir sebelum pra Islam. Hal ini kerana Islam merupakan agama yang harmoni dan bukan agama yang cuba menghapuskan adat tradisi. Namun begitu, adat tradisi yang ingin diteruskan hendaklah tidak bercanggah dengan syariat Islam. Menurut Coulson (1960), sarjana Barat yang mengkaji sejarah hukum Islam, Islam datang ke Tanah Arab tidak sepenuhnya menghapuskan adat tradisi. Terdapat elemen-elemen pra-Islam yang dihapuskan dan ditukar ganti oleh syariat tetapi pada masa yang sama banyak elemen pra-Islam yang dipelihara oleh syarak kerana tidak bercanggah dengan prinsip-prinsip Islam.

Malik Bennabi (1986) menegaskan, kebudayaan yang diwarisi sebelum Islam boleh diamalkan dengan syarat tidak wujud pertentangan antara ajaran Islam dengan adat tradisi lama hingga menyebabkan perubahan dan penukaran pada ajaran Islam. Beliau memperkenalkan teori al-ta'ayush (saling bersama atau kewujudan bersama) antara ajaran Islam dan adat tradisi selain Islam. Dalam erti kata lain, Islam datang ke suatu tamadun bukan cuba untuk menghapuskan segala bentuk budaya pra-Islam, tetapi cuba menyesuaikan budaya tersebut agar selaras dengan prinsip-prinsip syariat Islam.

Ros Aiza (2015) membawa ayat 200 surah al-Baqarah bagi menunjukkan kaedah alQuran dalam menghadapi sinkretisme. Adat tradisi yang diwarisi pada zaman pra Islam, telah diubah dengan memberi tafsiran islamik dan menggantikan amalan yang bercanggah dengan prinsip tauhid dengan nilai-nilai Islam. Islamisasi atau pengislaman tidak bermaksud usaha untuk menghapuskan secara total budaya tempatan sesuatu masyarakat. Hal ini kerana, tidak semua budaya tempatan itu berbentuk negatif dan dilarang syarak. Lantaran daripada itu, dalam Islam wujud kaedah Usul al-Fiqh iaitu prinsip الإبراءة الأصلية الأصليية ataitu 'segala sesuatu yang belum ada hukumya itu kembali kepada asal' (Abu Zahrah 1958). Segala unsur budaya tempatan yang kelihatan bertentangan dengan ajaran Islam tidak sewajarnya disimpulkan sebagai kegagalan proses Islamisasi atau menghasilkan fenomena sinkretisme, tetapi ia perlu dilihat sebagai proses Islamisasi yang belum selesai.

\section{Unsur Sinkretisme dari Saki-Baki Agama Terdahulu Hendaklah Ditapis dengan Proses Sintesis terhadap Kebudayaan Lama}

Sebelum agama Islam tersebar secara meluas di Nusantara, masyarakat Melayu pada ketika itu menganut kepercayaan animisme dan juga Hindu-Buddha. Kepercayaan yang menebal kepada agama nenek moyang menyebabkan pendakwah yang datang ke Nusantara cuba mengekalkan adat tradisi yang lama, namun mensintesis budaya baru hasil penerapan rapi dengan nilai-nilai Islam. Dalam sejarah peradaban Islam, elemen-elemen adat yang baik dan positif dalam agama pra-Islam akan dinilai dan diselektif untuk diamalkan. Paradigma selektif dan sintesis ini boleh dilihat umpamanya dalam aspek perkahwinan. Dalam tradisi Arab pra-Islam, terdapat pelbagai jenis pernikahan dalam Arab Jahiliyah. Antaranya pernikahan seperti yang berlaku pada hari ini 
iaitu seorang lelaki datang kepada wali perempuan, menyerahkan mahar kepada walinya dan berkahwin. Selain itu, nikah istibda iaitu seorang suami membawa isterinya kepada orang yang ingin diinginkannya dan mempelawa orang tersebut meniduri isterinya agar memperolehi cahaya mata seperti orang yang diinginkannya. Begitu juga wujudnya nikah al-rahth iaitu sejumlah lelaki yang bersetubuh dengan seorang wanita, nikah mut'ah iaitu pernikahan dengan batasan waktu tertentu (kontrak), nikah al-badal iaitu pernikahan dengan menukar-nukar isteri, nikah al-maqt iaitu menikahi bekas isteri ayah yang telah meninggal dunia, dan seumpamanya (Sayyid Sabiq 1995). Dengan datangnya Islam dalam tamadun Arab, hanya satu jenis pernikahan yang diterima dalam Islam sementara jenis-jenis pernikahan yang lain dihapuskan dan diharamkan. Hal ini membuktikan Islam bersifat kritis dan selektif terhadap adat-adat pra Islam dengan menerima elemen-elemen adat yang positif (sahih) dan menolak elemen-elemen negatif (fasid).

Hal yang sama berlaku dalam seni budaya wayang kulit yang turut mempunyai peranan yang penting dalam penyebaran Islam di Nusantara. Pada asalnya, seni ini dipengaruhi oleh pengaruh Hindu yang mula-mula datang ke Nusantara. Kisah-kisah Ramayana dan Mahabharatta sangat popular dalam wayang kulit. Setelah Islam datang bertapak di Nusantara, peranan Wali Songo kekal meneruskan adat kesenian ini kerana ia sebati dengan masyarakat, tetapi ia diubahsuai dengan melakukan sintesis dan selektif kepada watak-watak dalam wayang kulit. Ini dapat dilihat seperti dalam watak Dalang yang menggambarkan bagaimana Tuhan (Allah) menguasai dan mengendalikan makhluk-makhlukNya. Adat yang telah lama berakar umbi dalam masyarakat Minangkabau tidak dihapuskan secara total oleh para pendakwah tetapi ia perlu disaring, ditapis dan diselektif agar modifikasi adat itu bersesuaian dengan ajaran Islam seperti dalam Adat Perpatih (Mochtar 1998). Sikap selektif dan sintesis terhadap المحافظة على القديم الصالح والأخذ بemelihara nilai-nilai lama yang baik, dan dalam masa yang sama mengambil nilainilai baru yang lebih baik).

Sebagai kesimpulan, secara konsep dan teorikal, sinkretisme bukanlah suatu bentuk pemikiran yang membawa ideologi baru, tertentu dan khusus terhadap sesuatu aspek. Sebaliknya, sinkretisme merujuk kepada fenomena percampuran dan pembauran beberapa bentuk pemikiran atau falsafah atau agama yang bersifat tertentu. Dalam perbincangan para sarjana berhubung agama, istilah sinkretisme sering menimbulkan kontroversi kerana lazimnya ia diinterpretasikan dengan konotasi yang negatif. Hal ini kerana sinkretisme sering digambarkan dengan gambaran yang "tidak murni" dan "tidak tulen" dalam sesuatu ajaran atau agama. Ia disebabkan identiti bagi sesebuah agama lazimnya mempunyai perbezaan doktrin dengan agama yang lain. Fenomena sinkretisme sama ada dibolehkan syarak atau sebaliknya perlu dilihat dalam pelbagai perspektif sama ada ia melibatkan antara agama, falsafah mahupun budaya. Tidak semua saki baki kepercayaan lama itu terus dihapuskan.

\section{References}

Asyraf Ibn 'Abd al-Hamid Barqa'an. t. th. Mazahir al-Tasyabbuh fi al-'Asr al-Hadith wa Atharuha 'ala al-Muslimin. t.tp: t.p..

Basri Ibrahim. 2010. Hukum Penglibatan Orang Islam dalam Perayaan Bukan Islam dalam Konteks Malaysia. Jurnal Islam dan Masyarakat Kontemporari. 3: 93.

Brown, R. 2006. Contextualization Without Syncretism. International Journal of Frontier Missions 23: 3.

Colpe, C. 1987. Syncretism. Dalam The Encyclopedia of Religion. Eliade, M. (ed.) New York: Simon \& Schuster Macmillan.

Coulson, N. J. 1960. A History of Islamic Law. Edinburgh: University Press.

Cross, F.L. 1997. The Oxford Dictionary of the Christian Church. New York: Oxford Press. 
Dictionary of Philosophy and Religion. 1980. New Jersey: Humanities Press.

Encyclopedia of Philosophy and Pyschology. 1986. New Delhi: Cosmo Publications,

Encyclopedia of the World's Minorities. 2013. New York: Routledge.

Faisal Ismail. 1997. Paradigma Kebudayaan Islam: Studi Kritis dan Refleksi Historis. Yogyakarta: Titian Ilahi Press.

al-Ghazi, Muhammad Ibn Muhammad. t.th. Husn al-Tanabbuh Lima Warada fi al-Tasyabbuh t.tp: t.p.

Hamka. 1965. Tafsir al-Azhar. Jil. 30. Jakarta: Pembimbing Masa.

Hamzeh'ee, et. al. 1995. Syncretistic Religious Communities in the Near East. Leiden: Brill

Herlianto. 1996. Injil dan Sinkretisme. Journal Pelita Zaman. 11 (2): 1-2.

Ibn Hajar al-Haytami. 1987. al-Fatawa al-Fiqhiyyah al-Kubra. Beirut: Dar al-Kutub al-'Ilmiyyah.

Ibn Rusyd. 1980. Fashl al-Maqal fi ma Bayn al-Hikmah wa al-Syari'ah min al-Ittishal. Cairo: Dar al-Ma'arif.

Koentjaraningrat. 1984. Kebudayaan Jawa. Balai Pustaka, Jakarta.

Leopold, A. M. \& Jensen, J. S. ed. 2014. Syncretism in Religion. New York: Routledge.

Levinskaya, I. A. 1993. Syncretism, The Term and Phenomenon. Tyndale Bulletin. 1:117-128.

Malik Bennabi. 1986. Musykilah al-Thafaqah. Terj. 'Abd al-Sabur al-Shahin. Beirut: Dar al-Fikr.

Mochtar Naim. 1968. Menggali Hukum Tanah dan Hukum Waris Minangkabau. Padang: Center for Minangkabau Studies Press.

Muhidin Yusin. 1990. Islam di Sabah (Islam in Sabah). Kuala Lumpur: Dewan Bahasa dan Pustaka.

Mullins, M. R. 2001. Syncretistic Movements. Dictionary of Asian Christianity. Scott W. Sunquist. (ed.). Grand Rapids, MI: William B. Eerdmans.

al-Nadwi, 'Ali Ahmad. 1999. al-Qawaid wa al-Dawabit al-Fiqhiyyah al-Hakimah fi Mua'malat alMaliyah. t.tp. t.pt

Norazit Selat. 1989. Konsep Asas Antropologi. Kuala Lumpur: Dewan Bahasa dan Pustaka.

Oxford Dictionary, Thesaurus and Word Power Guide. 2001. New York: Oxford University Press Inc.

Pinto, J. 1985. Inculturation Through Basic Communication. Banglalore: Asian.

Radwan, Chad Kasseem. 2009. Assesing Druze Identity and Strategies For Perserving Druze Heritage in North America. Disertasi Sarjana. University of South Florida.

al-Raysuni, Ahmad. 1995. Nazariyyah al-Maqasid 'Inda al-Imam al-Syatibi. Riyadh: al-Dar al'Alamiyyah lil kitab al-Islami.

al-Razi, Fakhr al-Din. 2000. al-Tafsir al-Kabir. Beirut: Dar al-Kutub al-'Ilmiyyah.

Robbins, J. 2011. Crypto-Religion and the Study of Cultural Mixtures: Anthropology, Value, and the Nature of Syncretism. Journal of the American Academy of Religion. 79 (2): 408-428.

Ros Aiza Mokhtar \& Che Zarina Sa'ari. 2015. Konsep Sinkretisme Menurut Perspektif Islam. Jurnal Afkar. $17: 54$.

Ros Aiza. 2015. Konsep Sinkretisme Menurut Perspektif Islam: Kajian Terhadap Adat Dan Kepercayaan Masyarakat Kedayan. Tesis kedoktoran, Akademi Pengajian Islam Universiti Malaya.

Saipuddin Salleh. 2003. Talfiq dalam Perkara Ibadat di Kalangan Masyarakat Islam di Malaysia: Satu Penilaian Hukum. Disertasi Sarjana. Akademi Pengajian Islam Universiti Malaya.

Salman Adwah. 2003. Rasail Ila al-Hajj. Riyadh: Maktabah al-Rushd.

Sayyid Sabiq. 1995. Fiqh al-Sunnah. Cairo: Dar al-Fath li al-A'lam al-`Arabi.

Schineller, P. 1992. Inculturation and Syncretism: What is the Real Issue? International Bulletin of Missionary Research. 2 : 50-53.

Schreither, R. 1994. Constructing Local Thelogies. Maryknoll: Orbis.

Scott, M. A. 2000. Syncretism in Evangelical Dictionary of World Missions. Grand Rapids, MI: Baker Books. 
Suraya Sintang. 2003. Fenomena Sinkretisme-Islam Dalam Adat Resam Masyarakat Bugis: Kajian Kes Daerah Tawau, Sabah. Seminar Zaba Mengenai Alam Melayu 1, Nilai-Nilai Peradaban Melayu, 12-14 August 2003.

The Concise Oxford English Dictionary. 2011. ed. New York: Oxford University Press.

The New Encyclopaedia Britannica. 1976. Chicago: Encyclopaedia Britannica Inc.

Wahbah al-Zuhayli. 1993. al-Rukhas al-Syar'iyyah Ahkamuha wa Dawabituha. Beirut: Dar alKhair.

Zariwh, Abd al-Haq, et al. 2016. Al-Insan wa al-Mujtama'. Algeria: Kulliyah al-'Ulum alInsaniyyah wa al-'Ulum al-Ijtimaiyyah, Jami'ah Tlemcen.

\section{Interview}

Hj. Hussin bin Hj. Hassan. Berumur 70 tahun dan berasal dari Kampung Bugaya Semporna Sabah. Interview: 16 January 2016.

M. Bambang Pranowo. Professor di UIN Jakarta dan Rektor di Universitas Mathla'ul Anwar, Banten. Interview (emel): 23 March 2016.

Mualimin Mochammad Sahid. Pensyarah Kanan, Fakulti Syariah dan Undang-undang, Universiti Sains Islam Malaysia. Interview: 4 April 2016.

Sumanto al-Qurtubi. Pensyarah Kanan, Department of General Studies, King Fahd University of Petroleum and Minerals, Kingdom of Saudi Arabia. Interview (emel): 5 April 2016. 